\title{
From Spatial Data to Synchronised Actions: The Network-centric Organisation of Spatial Decision Support for Risk and Emergency Management
}

\author{
Jeroen M. M. Neuvel • Henk J. Scholten • \\ Adri van den Brink
}

Received: 18 May 2009/Accepted: 2 November 2010 /

Published online: 20 November 2010

C) The Author(s) 2010. This article is published with open access at Springerlink.com

\begin{abstract}
A considerable amount of the required information in risk and emergency management is geographical, but this information does not always reach the right actors at the right time, so how can geographical information be organised in such a way that it supports risk and emergency management more effectively? The answer requires a conceptualisation of risk and emergency management practices resulting in the network-centric concept, which implies that those involved in risk and emergency management are connected and that they have the capability to share and access information. The concept was made operational through the development of an information system and the exchange of geographical information within the system was facilitated by the use of peer-to-peer networking in combination with a client server network. On the application level, the information was presented in both map and text forms to support the exchange of information between actors. This way of organising geographical information and technology leads to improved information and communication, better situational awareness and faster decision making.
\end{abstract}

Keywords Network-centric $\cdot$ Spatial information infrastructures $\cdot$ Emergency management $\cdot$ Risk management

J. M. M. Neuvel $(\square)$

Centre for Urban and Environmental Development, Saxion University of Applied Sciences,

P.O. Box 70.000, 7500 KB Enschede, The Netherlands

e-mail: j.m.m.neuvel@saxion.nl

\section{H. J. Scholten}

SPINlab / Institute for Environmental Studies, Vrije Universiteit Amsterdam, De Boelelaan 1087, 1081 HV Amsterdam, The Netherlands

A. van den Brink

Landscape Architecture Group, Wageningen University, P.O. Box 47, 6700 AA Wageningen,

The Netherlands 


\section{Introduction}

Recent emergencies and emergency response exercises have highlighted major information deficiencies in risk management (activities related to the prevention and mitigation of risks) and emergency management (including activities related to emergency training, response and short-term recovery). Important information did not reach the right organisations and people at the right time, resulting in unnecessary loss of life and property (Kevany 2003; National Research Council 2007; Van de Ven and Van den Berg 2007).

The Dutch Bonfire exercise in 2004 illustrated the type of information deficiencies that can appear (COT et al. 2005). This particular exercise dealt with the potential threat of a terrorist attack in the Rotterdam harbour and an attack on the Amsterdam Arena stadium. During the exercises, important individuals such as the National Coordinator for Counterterrorism and the Director-General for Public Safety and Security as well as the ministerial and inter-ministerial policy teams, were not provided with integrated information on time and in a consistent way. Some information was available to other organisations but was not actively requested by organisations in need of this information. The national coordination centre was unable to integrate information from different sources, and thereby unable to get a more complete overview of the current situation. Moreover, the emergency rooms of the police department, fire department and the medical services had only a limited overview of the situation at the scene of the attacks, which also hampered effective decision making. Clearly then, information management is crucial in risk and emergency management, but important information does not always reach the right services and individuals at the right time, thus constraining effective mitigation, preparation, response and recovery.

In addition to the recognition of information in general as crucial element, geospatial information in particular is regarded as indispensable. A considerable part of the information required before and during emergencies contains a specific spatial reference, such as the location of toxic clouds or flooded areas or the location of emergency services. For this reason, much effort is put into the development of geoinformation and communications technology (Geo-ICT) or geotechnology for risk and emergency management (Cova 2005; Greene 2002; Kevany 2003; Köhler and Wächter 2006; MacFarlane 2005; National Research Council 2007; Parker et al. 2007). Consequently, the organisation of geographical information and consequently geotechnology requires special attention in addition to the organisation of information in general. This paper focuses on the question of whether geoinformation and geotechnology can be organised in such a way that it supports decision-making processes within risk and emergency management more effectively.

The research is based on the idea that the search for an appropriate role for geoinformation and geotechnology in risk and emergency management should not start with a particular technology, but with a conception of risk and emergency management activities. This statement follows Klosterman (2001) who argued that the search for an appropriate role for computer-based information and methods must begin with the conception of the activity that should be supported. A technology driven approach can limit our view resulting in a focus on those aspects of risk management and emergency management for which a particular technology or tool 
is appropriate, but neglecting other vital elements of risk and emergency management activities. As a result, the technologies may not meet the particular needs of the risk and emergency managers. For this reason, the central research objective is to develop a conception of risk and emergency management which can be used as a basis for the organisation of geographical information for decision support in general.

\section{Research Strategy and Method}

A conception of risk and emergency management can be developed in different ways. On the one hand, this conception can be obtained deductively, implying that knowledge of individual phenomena is derived from universal laws. Consequently, general ideas about emergency response can be applied to individual practices and these general ideas can be used as starting point for the organisation of geoinformation and geotechnology in these practices. On the other hand, the conception can be obtained inductively. A conception of risk management can be based on studying particular risk management practices through which more general concepts and mechanisms are highlighted. Abduction can be regarded as a way to mediate between inductive and deductive reasoning. Similar to induction, the starting point of abduction is in the specific rather than the general. The researcher looks at particular situation-specific phenomena; he/she does not only describe these phenomena, but also makes new interpreting links (Danermark et al. 2002). The examined risk and emergency management practices can be interpreted through existing ideas e.g. from the literature or other examined practices. Through this interaction between the individual observations with more general ideas derived from the literature or experiences with previous practices, a specific conceptualisation of the risk and emergency management practices at hand is developed. This strategy reflects the strategy of our conceptualisation of risk and emergency management.

Our conceptualisation of risk and emergency management is based on two different projects: the GeoRisk project (www.georisk.nl) and the Geo-Data Infrastructure for Disaster Management (GDI4DM) project (www.gdi4dm.nl) in the Netherlands in which the authors participated. The GeoRisk project focussed on activities related to risk management in spatial planning. These activities were studied through examining planning practices with respect to the consideration of flood risks and industrial risks in spatial planning. Moreover, information requirements for dealing with risks in planning were considered (Projectconsortium Georisk 2008). The project consortium included three universities, three research institutes, two consultancy companies, one municipality, one province, the directorate-general for Public Works and Water Management (Rijkswaterstaat-DWW) and one safety region. Safety regions are responsible for emergency response. In the Netherlands, emergency management services are organised regionally. The country is divided into 25 safety regions and each safety region, which includes several municipalities, consists of a police department, fire department, and medical and paramedical services.

Within the GDI4DM project, emergency response processes were studied through examining information and system requirements of the actors involved in emergency 
response (Neuvel and Zlatanova 2006; Snoeren 2006). Ideas on risk and emergency management found in external literature were used as an interpreting framework to make links between the different initial conceptualisations of risk and emergency management resulting from the examination of risk and emergency management practices.

Whereas the GeoRisk project mainly focussed on the way spatial planners deal with safety risks and on the requirements for geotechnology in spatial planning, the GDI4DM project also aimed at developing Geo-ICT. Within this project, the conception of emergency management was made operational in principles for spatial information infrastructures (SIIs) for emergency management at the regional level. Based on these principles, an information system was developed to support command and control, referred to as Eagle, The safety region Gelderland Midden, located in the east of the Netherlands (see also Fig. 6), asked Geodan to modernise its existing Command \& Control System, adjusting it to the network-centric work approach. In close cooperation with the Gelderland Midden region, ESRI, Microsoft and the Ministry of Defense and Homeland Security, Geodan developed the Eagle system. This system was tested and evaluated in the GDI4DM project during a regional emergency exercise known as Eagle One (Brooijmans 2008; Geodan 2008; Riedijk et al. 2008; Van Capelleveen 2008; Van de Ven 2008). The Gelderland Midden safety region is using Eagle in emergency trainings and regional crisis situations.

The GDI4DM project consortium also included three universities, one 'safety region', one municipality, one province, the cadastre and the directorate-general for Public Works and Water Management (Rijkswaterstaat-RWS). The GDI4DM project can be regarded as one of the leading projects on this topic in the Netherlands, since the Eagle One exercise was awarded the Public Safety Award in 2008. The jury of this award consisted of 11 key figures on public safety from the Government and knowledge institutes including professors, mayors and directors of emergency services and research institutes. The Eagle application, which uses Microsoft technology, was also highlighted by networkworld as an innovative Microsoft research project (www.networkworld.com).

This paper describes and reflects on the findings of these two projects. In the following section, a conception of risk and emergency management is discussed, resulting in the concept of network-centric risk and emergency management which was used as point of departure for the development of Eagle to support emergency management. Subsequently, the added value of geoinformation and geotechnology for network-centric risk and emergency management is described. We then discuss the architecture and applications of Eagle and the experiences with Eagle in the Eagle One emergency management exercise. In the concluding section, we reflect on the use of the network-centric approach as concept for the organisation of geoinformation and geotechnology in risk and emergency management.

\section{The Conceptualisation of Risk and Emergency Management}

The conceptualisation of risk and emergency management was a process that took place from the writing of the project proposal at the beginning, until the evaluation 
of the use of geoinformation in the emergency training at the end. The resulting conception of risk and emergency management can be summarised in three key principles, which in the end resulted into the conceptualisation of risk and emergency management as network-centric operations:

- risk management and emergency response is a collaborative process, which implies the connection of all the actors involved;

- collaboration requires a shared situational awareness; and

- collaboration and a shared situation awareness require the sharing of information.

First of all, risk and emergency management was recognised as a collaborative process. Collaboration between safety experts and spatial planners was regarded as crucial for the consideration of safety risks in spatial planning (Projectconsortium Georisk 2008). Through this collaboration, both safety issues and potential ways to deal with the safety issues could be addressed in the planning process and a commitment for the consideration of safety risks could be created. Moreover, during an emergency response, cooperation between actors is required for effective action. During an evacuation, for example, the police department will be responsible for traffic management but the municipalities are responsible for communication with citizens (Diehl and Van der Heide 2005). Consequently, emergency response has to be carried out by multiple agencies in which both vertical and horizontal coordination is required, requiring the collaboration of all the actors involved. Establishing connections can be regarded as an important challenge, since actors involved in emergency response are often spread out between different organisations which may have different physical locations. Moreover, actors within one organisation may also be spread out in the field or between offices.

In addition, collaboration requires a shared situational awareness. When there is a weak section of dike but actor A assumes that it is on the left side of the river bank and actor B believes that it is on the right side, collaboration to deal with the specific weak spot will be confused. Collaboration in spatial planning also requires shared situational awareness. For example, when spatial planners and safety experts have different knowledge about the nature and amount of hazardous materials in a particular installation, they will apply different safety distances for urban developments in the vicinity of the site. Shared situational awareness is located in the mind, rather than being available in an information system or in other media such as a handbook. Shared situational awareness therefore differs from the term common operational picture; for example, when the information system shows that the weak dike section is on the left side, but actor B interprets it as the right side, there is a common operational picture of the situation, but not a shared situational awareness.

Collaboration and shared situation awareness, however, require the sharing of information. Information and communication are recognised as central elements in both risk and emergency management. Information is a prerequisite for situational awareness, which allows collaboration and coordination of these actions. The exchange of information is regarded as time critical, especially in emergency response. A common operational picture, as well as a shared situational awareness, requires the exchange of valid and up-to-date information between all the involved actors at the same time. The information that has to be distributed can consist of information that already exists prior to an event such as information about 
topography or contingency plans but also of information that becomes available during an event, referred to as in situ information, such as intelligence about a collapsed dike or on the geographical position of the emergency services.

Ideas about network-centric operations were useful for structuring the principles of risk and emergency management because similar to the presented ideas on risk and emergency management, the concept of network-centric operations has collaboration as point of departure. Moreover, the concept explicitly specifies the role of information in these collaborative process from which informational and system requirements can be derived, which also fitted in the principles of risk and emergency management that were developed already within the project. For these reasons, 'network-centric risk and emergency management' was used as the interpreting framework through which the different conceptualisations of risk and emergency management can be structured and integrated. The term network-centric is derived from a military context where 'network-centric warfare' is the term used for the US military response to the information age. It implies that military operations are enabled by the networking of the armed forces and this networking takes place in the physical, information and cognitive domains (Alberts et al. 2001). The physical domain is the domain that the military seeks to influence, and includes the activities or events in a particular area that need to be controlled. The information domain is the domain where information is created, manipulated and shared. The cognitive domain is regarded as the domain of the mind of the actors involved in warfare which includes tactics, strategies and techniques. Principles of networkcentric warfare can also be applied to other fields so we can speak of network-centric operations that have been applied to emergency management as well (Von Lubitz et al. 2008a, b). If applied to risk and emergency management activities, we can speak of 'network-centric risk and emergency management' (NCREM) (Table 1).

The physical domain then involves the area that the risk and emergency managers seek to influence. The information domain includes the information created and needed for effective risk management and response and here a distinction can be made between data and information. Data can be regarded as the basic descriptive characteristics of things and placed in a comparatively raw format such as observations, counts, measurements, locations or attributes, whereas information is regarded as more processed, organised, summarised, selective and user friendly, with the intention of assisting correct interpretation (Parker et al. 2007). The common

Table 1 Characteristics of network-centric risk and emergency response

\section{Domain Characteristics}

Information The actors involved in risk and emergency management have the capability to share, access, produce and gather information in a network-centric way instead of hierarchically. Of course, this information should be valid, complete, accurate and up to date.

Cognitive The actors involved in risk and emergency management have developed an awareness and shared understanding about what's going on, what can be done and what should be done.

Physical The actors involved in risk and emergency management work together to influence the physical domain such as the area that is or can be flooded to reduce both the damage and the number of victims. 
operational picture, for example, can be regarded as information. The cognitive domain is located in the mind and involves, amongst other things, situational awareness that can be constructed from the information in the information systems but can also result from other information e.g. resulting from face-to-face contact or telephone contact. Moreover, existing cognitions or elements in the cognitive domain shape observations and the interpretation of information. Previous experiences, feelings, intuitions and values can greatly influence the perception of information (see, for example, Te Velde et al. 2002). In this respect, wisdom, referred to as the capacity to make value judgements based on knowledge (Walter 2005), can be regarded as a factor which influences situational awareness

These different domains are highly connected (Von Lubitz et al. 2008a). Improved information sharing through networks, for example, should result in a common operational picture and subsequently in shared understanding in the cognitive domain and into synchronised actions in the physical domain, which should result in better collaboration and subsequently in better decisions and the reduction of disaster impact, as illustrated in Fig. 1.

\section{The Added Value of Geotechnology in NCREM}

Within previous evaluations of the use of information in risk and emergency management, it was mentioned that crucial information was either not available or not shared (ACIR 2005; National Research Council 2007). Geotechnology can contribute to the organisation of the information domain through its tools for

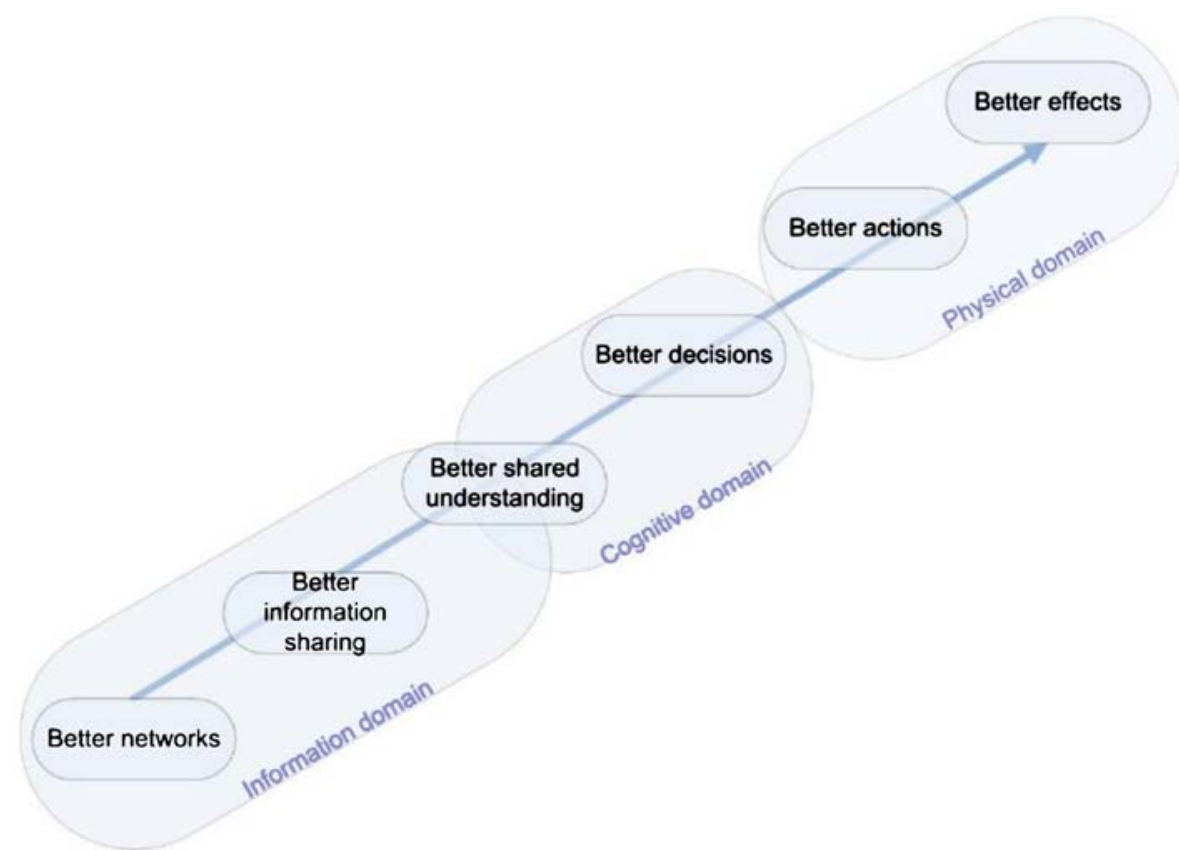

Fig. 1 The relationship between the information, cognitive and physical domains Source: Brooijmans (2008) 
gathering, processing, sharing and presenting information (MacFarlane 2005). This can be regarded as a prerequisite for creating situational awareness, synchronising actions and, finally, limiting disaster impact effectively. First of all, geotechnology can support the collection and subsequent integration of relevant spatial data, such as population or topographic data, which can be brought together in comprehensive databases. Subsequently, these data can be used for further analytical operations like the selection of areas higher than one metre above sea level or the calculation of the number of people living in a specific area. Through these static operations, a descriptive model of an area can be developed, which can result in an initial operational picture of the area or the event (see, for example, Köhler and Wächter 2006; MacFarlane 2005; Van de Ven et al. 2008; Zerger 2002). Furthermore, modelling functions can be included within geo-tools which can be used for scenario development, e.g. to explore flood patterns resulting from breaches of dikes in different locations. These tools are especially useful when the risk, e.g. the particular location of a dike breach, is not fully known. Assessment tools can be used to identify the consequences of flooding in the light of different objectives, e.g. damage reduction or the reduction of casualties, to explore different alternatives. In addition, geotechnology can support the visualisation of information through maps, charts, graphs, tables, animations or 3D graphics and such images can support actors involved in risk and emergency management (MacFarlane 2005). Moreover, geotechnology can contribute to the exchange of geographical information through which collaboration can be supported as discussed previously. Spatial information infrastructures (SIIs), also referred to as geo-data infrastructures (GDIs) or spatial data infrastructures (SDIs), can be regarded as the central concept for creating interoperable systems and enabling the exchange of geographical data and information. This exchange requires technical standards such as ISO standards, access networks such as the internet, policies such as those on conditions for data sharing and guidelines on responsibilities towards information production and maintenance of required spatial data sets, and, last but not least, individuals who use the spatial information, together with information suppliers and any value-adding agents in between (Mansourian et al. 2006; Williamson and Rajabifard 2003). In this respect, an appropriate SII that enables the exchange of information is increasingly considered a critical aspect to support risk and emergency management activities (Cutter 1996; Greene 2002; Grothe et al. 2008; Köhler and Wächter 2006; Mansourian et al. 2006; Parker et al. 2007; Scholten et al. 1998).

It has been argued that major events and crises, even though they seem structured problems in the beginning, will inevitably pass into the unstructured domain in due course (French and Niculae 2005). This unstructured character can hamper the use of geotechnology since, when it is unclear which problems should be tackled and which objectives should be met, it is also hard to use geo-tools for analysis. Nevertheless, this point was nuanced within the GDI4DM project. Even within these chaotic circumstances, structured working processes can be recognised, such as alerting or source and effect control (Diehl and Van der Heide 2005; Dilo and Zlatanova 2008; Fruijtier et al. 2009; Snoeren 2006). The problems that need to be tackled within these working processes as well as the objectives that should be met can be well defined in advance, i.e. through contingency planning. In addition, a considerable part of the informational requirements could be defined beforehand. 
Clearly then a chaotic, unstructured event contains both structured, semi-structured and unstructured subproblems, which can be supported through geotechnology. Moreover, geotechnology can stimulate communication and collaboration between actors, which is regarded as crucial under chaotic circumstances (French and Niculae 2005). Comparable arguments can be made in the context of risk management. Even though a planning problem, e.g. on the desired land use in the future, can be unstructured, the risk management problem within the planning process can be structured or semi-structured. Moreover, the information derived from the geo-tools can be used in discussions, e.g. as idea or argument to structure problems and objectives (Shulock 1999; Weiss 1991).

\section{Towards an Architecture for Geo-enabled NCREM}

The principles for NCREM have only been made operational through a system for supporting emergency management. Nevertheless, the experiences with these emergency management systems are also relevant for risk management as discussed in the concluding section. Even though massive investments have been made in the development of geo-tools and SIIs, the special needs of emergency management have rarely been addressed (National Research Council 2007). To meet the requirements for network-centric risk management and emergency response, new geographical systems and especially architectures have had to be developed. One major challenge associated with the architecture for a geo-enabled network-centric software solution lays in the connection of all the people, organisations, services and networks through which existing and in situ data were made available and easily accessible when needed. A mobile first responder in a crisis situation, for example, has to be able to get up-to-date geoinformation from the disaster management service. Nevertheless, during a disaster, a constant availability and capacity of the network cannot be guaranteed, especially not for field workers. Therefore, peer-topeer (P2P) networks were used to connect the actors in the field with each other and with the actors in the coordination centres.

While quite common in military command and control systems, the P2P technology is still insufficiently explored in civil applications and especially in emergency response situations (Bortenschlager et al. 2007). A P2P network differs from a more traditional client-server architecture in which a relatively low number of servers provide information to different clients or applications. Strictly speaking, a P2P network does not make a distinction between 'clients' and 'servers', but consists of equal entities, i.e. peers or nodes, which can serve both as clients and servers to other nodes. These nodes can be linked with each other via ad hoc connections and allow for sharing of a large number of data, including real-time data. The P2P technology enables systems to be functional when a constant network connectivity with a server could not be guaranteed, since a P2P network allows the exchange of information via other nodes available, either through a wireless local area network (WLAN) or mobile network or using ad hoc P2P networks (Bortenschlager et al. 2007) (Fig. 2).

Within Eagle, the client-server approach and the P2P technology were integrated into one system architecture as shown in Fig. 3. This architecture consist of four 

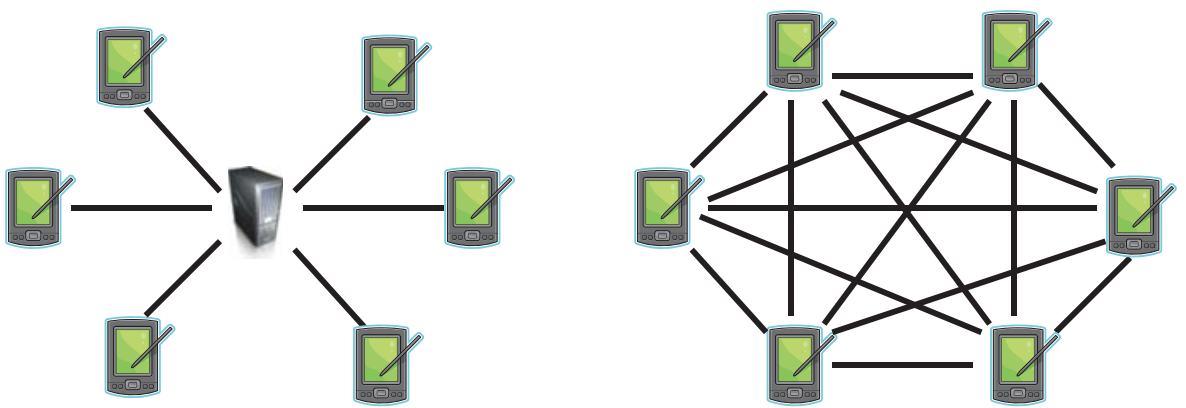

Fig. 2 A client-server (left) versus peer-to-peer network (right)

major elements: 1) A P2P environment where the information is exchanged between the involved organisations and people using a P2P network. 2) the centralised server environment making the information available to non-P2P clients. Several organisations work with certain client software which do not support OGC

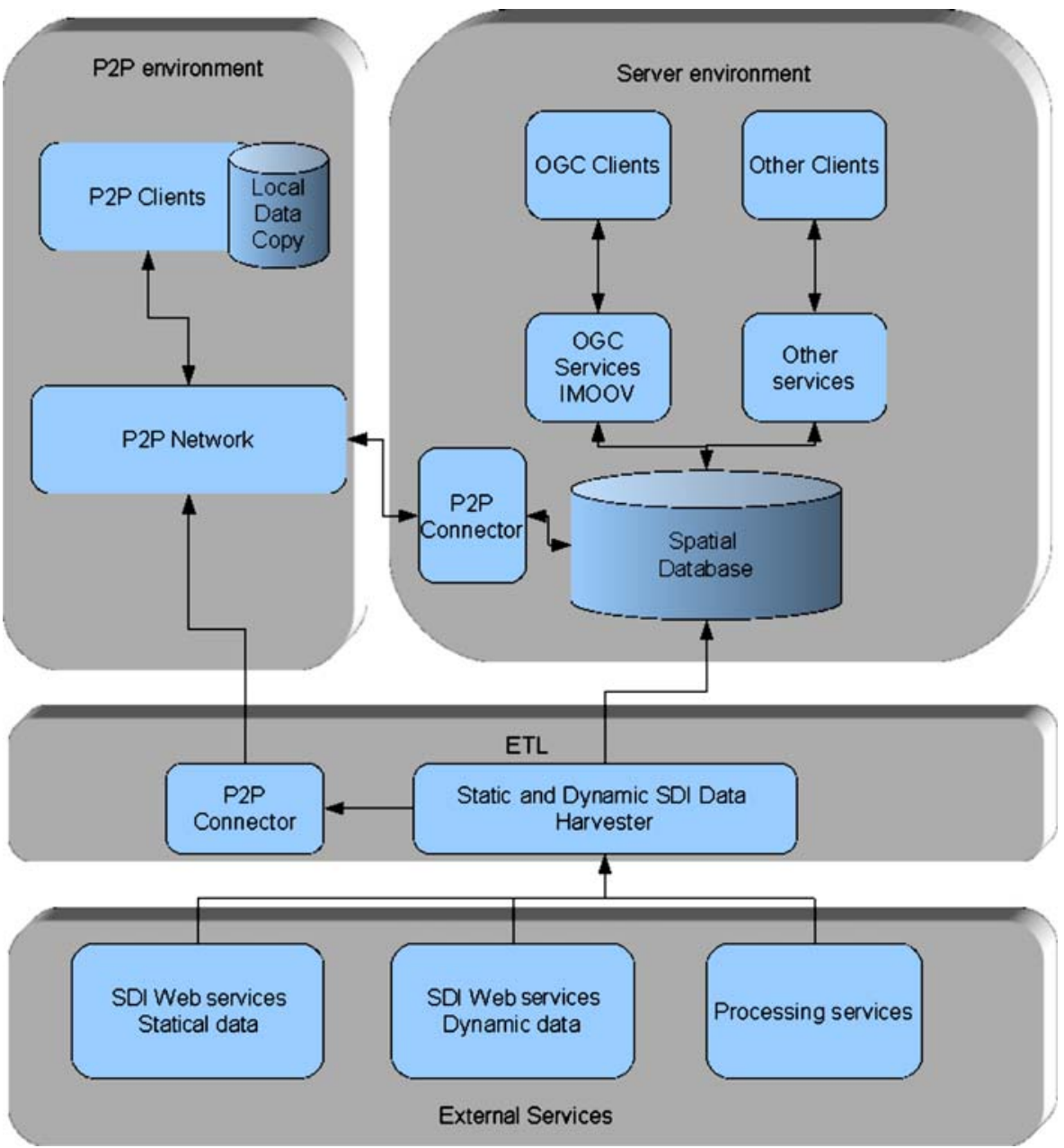

Fig. 3 The Eagle system architecture 
standards, like Microsoft Sharepoint, or require support for specific interfaces like the ESRI processing services. Therefore, besides the OGC compliant services, other service interfaces had to be implemented. The P2P connectors connect the P2P environment with the server environment (in both directions) and is used to feed data from the external services into the P2P network. 3) ETL (Extract-Transform-Load): extracts information from the external web services, transforms this into the data model used by Eagle and loads the transformed information into one or more databases and/or distributes the information on the P2P network. 4) External services, which were data repositories of various organisations which could possess valuable geoinformation such as citizen and building registers, meteorological and statistical data. information. The organisations and institutions maintaining these data repositories were supposed to provide 24-7 access to their servers and applications. The Netherlands, for example, has identified approximately 30 of such data sets and the responsible organisations will be obliged to provide OGC services for access. The generated information is retrieved from the P2P network and stored in databases (Dilo and Zlatanova 2008). Of course, calling the services directly has the main advantage of providing the most recent information. However, if these services are not available or overloaded, the information that was retrieved previously by another P2P client can be used instead. Consequently, data can be distributed either using the P2P network or directly from the system itself.

With respect to the information that should be exchanged through the networks, the definition of well-defined standardised services for discovery and exchange of geo-information is required. Geoinformation services refer to the processing of geodata which result in processed information, e.g. the potential water depth at a particular point or the fastest route from A to B (Annoni et al. 2005; Drummond and French 2008; Scholten et al. 2008). These services can be acquired from a great variety of available user-specific systems and can be presented in different applications, to meet specific user requirements and user interfaces and to enable the implementation of services from one application into another.

Such services are closely related to the development of SIIs. Initiatives for SIIs are in progress at many levels all over the world, e.g. INSPIRE in Europe (www.ec-gis.org/ inspire). These have to be further enriched to be able to serve the emergency sector. Large international projects, e.g. ORCHESTRA (www.eu-orchestra.org), OASIS (www.oasis-fp6.org) and WIN (ww.win-eu.org) have been reporting results of their research in this area. Proposals for standards and services developed within these projects are in process of discussion within the Open Geospatial Consortium (OGC, www.opengeospatial.org). However, all these services designed for client-server architecture can be made available within the P2P network. Selecting the relevant data and services required extensive investigations of user requirements and formal specifications of the emergency response processes and the data created and required within each sub-process of emergency response (Dilo and Zlatanova 2008; Snoeren 2006). For that reason, a two step approach was applied: (i) the design of a conceptual model of emergency management processes and data requirements, using Unified Modelling Language (UML), and (ii) deriving a data model.

On the visualisation and communication level, special attention was given to the creation and exchange of the common operational picture. Traditionally, this common operational picture was presented and exchanged through static situation 
reports, which were spread in a hierarchical way. These reports have been very useful to inform actors involved in emergency response about the actual situation. Nevertheless, three main drawbacks with respect to these traditional situation reports, were recognised (Van de Ven et al. 2008). First, it took time for situation reports to arrive at other teams, especially at teams at the higher level. Second, situation reports provided a static view of the dynamic situation. Consequently they were often out-dated. Third, not everybody who needed the information had access to the information. In addition to these drawbacks, it should be mentioned that situation reports often consisted of pages of text, which required time for reading.

As a way to deal with these drawbacks, two alternative interfaces were used together: SitPlot and SitText. SitPlot (Fig. 4) is a geographic interface based on ESRI's ArcGIS that allows its users to view, analyse and generate geographical information that is needed for decision making, such as information on current or potential water depth at a specific location. Figure 4 represents a screenshot of the SitPlot application at the beginning of an emergency exercise. It presents the area in which one of the emergency response exercises took place. On the left-hand side, different data layers, including reference and thematic data, can be selected such as topographic maps or maps with information about the population in the area. On the right-hand side, information about the incident can be added such as the location of the incident or the location of emergency services. The shared picture as presented in SitPlot results from the inputs from the different sections within the regional operational team (see also "Experiences from the Eagle One Exercise") and is available on every pc on which Sitplot is installed and activated. Consequently, people who need access to the situation reports can have access to these reports. Moreover, the report can be accessed quickly after they are disseminated. Users can add maps to SitPlot, e.g. maps which represent the location of an incident or the accessibility of an area, and these maps then become available as separate map layer in SitPlot. Plotters in the information-section take care of the integration of the added

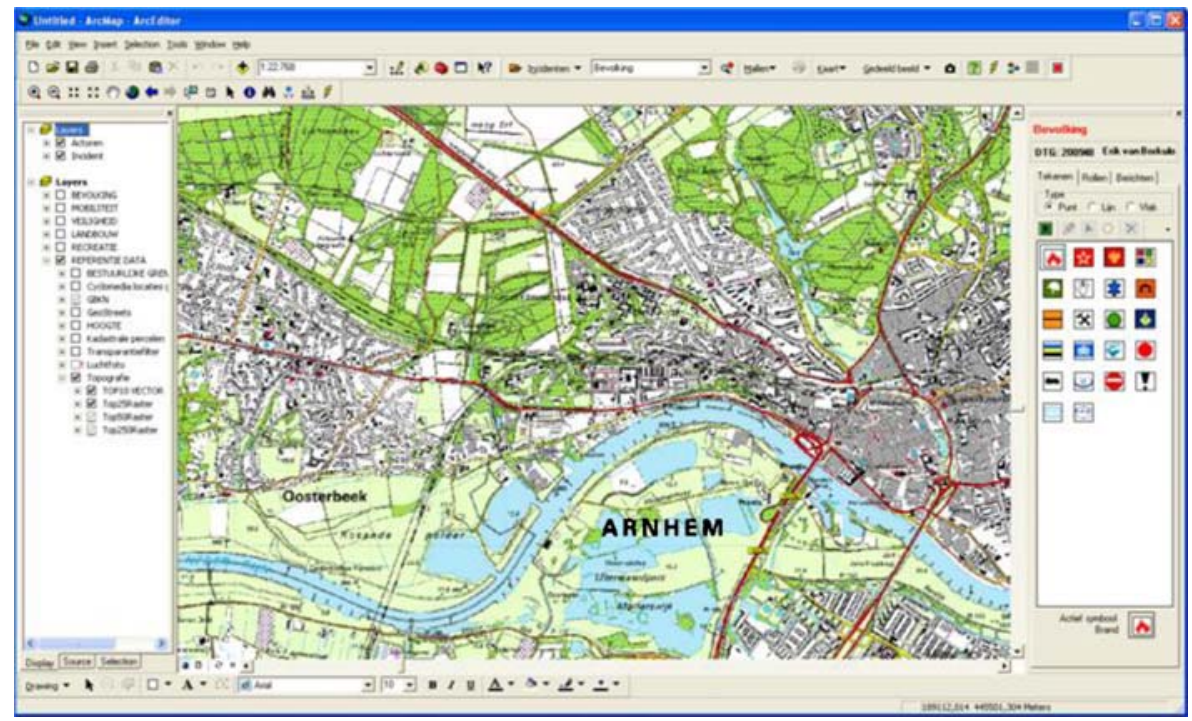

Fig. 4 SitPlot 
maps. In addition, they can carry out analytical operations within SitPlot in order to meet specific information requirements of various sections of the regional operational team during the exercise, such as an analysis of the number of people that will be affected by a toxic cloud. Consequently, the situation reports are no longer static, but dynamic. In addition, new possibilities for visualisation and communication of situation reports are added, since SitPlot also allows analytical operations.

SitText (Fig. 5) is a collective workspace used for storing and exchanging texts. It allows its users to send and receive short text messages. SitText consisted of different tabs for different groups of users such as the fire department of the police department. Figure 5 represents an example of SitText, which represents the situational report during one of the exercises. It contains information about various aspects of the emergency such as the weather conditions i.e. temperature $20^{\circ}$, wind, Northeast 5; the nature of the incident, i.e. a train accident; the nature and direction of the released hazardous materials; the possibilities for emergency response i.e. some roads are blocked; the number of people affected together with an indication of the seriousness of their injuries and the actions undertaken i.e. emergency services have entered the train, the water board is warned. On the left-hand side, it is indicated which users are online. On the top, the different tabs can be selected. Through SitPlot and SitText, a more dynamic view of the actual situation could be given, which could be exchanged with the actors involved in emergency management in a fast and efficient way.

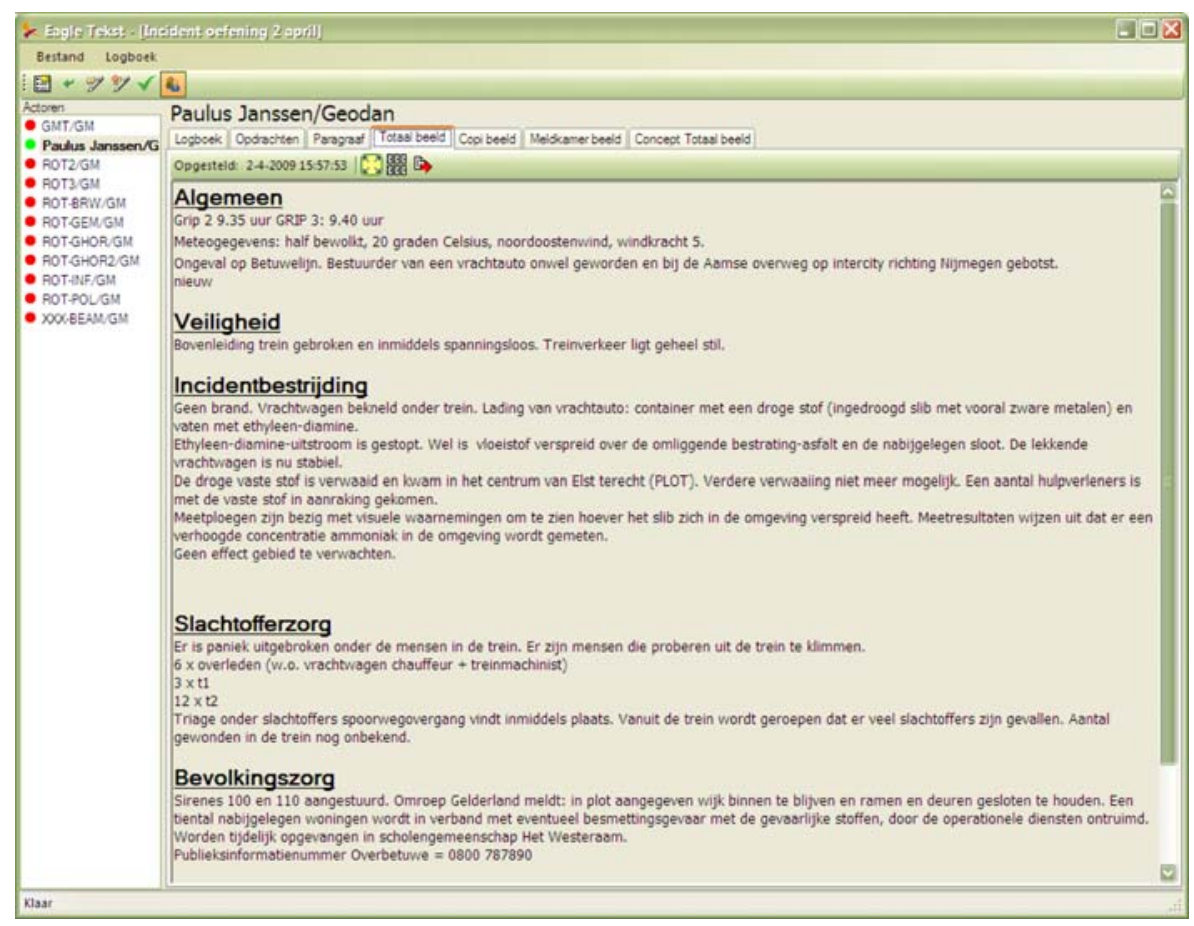

Fig. 5 SitText 


\section{Experiences from the Eagle One Exercise}

In the Netherlands, most emergency incidents of a minor nature are responded to at the local level by the emergency services including the fire brigade, paramedic teams and the police department. When there is a need for a structured coordination, a coordination team of representatives of the emergency services is formed at the site of an incident. When the magnitude of the emergency increases, other parties at other administrative levels can become involved and a regional coordination team is formed. This coordination team is often situated in the regional emergency operations centre of the safety region remote from the incident and consists of representatives of the emergency services and the municipality. The mayor of the municipality in which the incident is taking place has the administrative lead within the regional coordination team. The nature of a disaster may require the need for the involvement of additional, specialised organisations such as the water board in case of a flooding. When the potential magnitude of an incident leads to a serious threat to a large section of the community in the incident vicinity, to the environment, or to anticipated severe damage to property, emergency officers at provincial or national level are involved (Ministerie van Binnenlandse Zaken 2003; Scholtens 2008).

The Eagle One exercise focussed on the regional level and took place in the Safety region Gelderland Midden, in the Gelderland province, located in the east of the Netherlands (Fig. 6). The central objective of Eagle One was to test and evaluate the use of information and geotechnology through testing the Eagle applicationsystem.

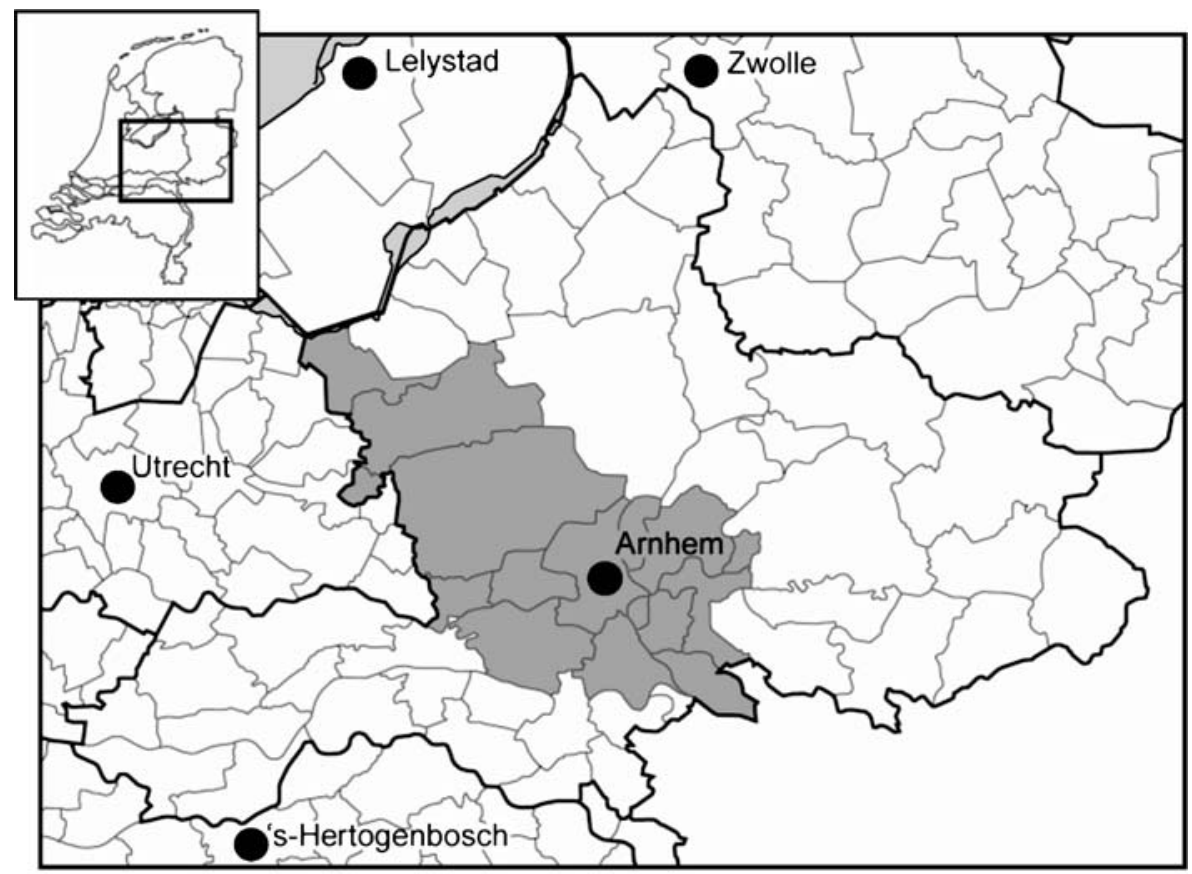

Safety region Gelderland-Midden

Fig. 6 Safety region Gelderland Midden 
Eagle was applied in the regional operational team of the regional coordination centre. The regional emergency operations centre consists of a policy team, mainly focussed on decision making, and an operational team, which advises the policy team and executes the strategies developed by the team. The regional operational team communicates with both the policy team and with the actors in the field on the site of the incident. The regional operational team itself consists of eight sections: Information management; Fire department; Police department; Paramedics; Logistics; Municipality; Information services; and Third parties, consisting of organisations with specific expertise such as the water board during a flood or electricity companies during a power breakdown. The focus of the exercise was on the regional operational team. Proposed actions in the regional operational team were not executed and practiced in the field.

During the exercise, every section of the regional operational team was observed and particular attention was paid to the information domain in general and the communication process and the use of information and information systems in particular. The exercise was also evaluated in a plenary session with the participants. In addition, participants in the exercise were asked to fill in an online questionnaire. Within this questionnaire a distinction was made between users that used only SitPlot, referred to as SitPlot respondents and users that used both SitPlot and SitText, referred to as SitPlot and SitText respondents (Table 2). The observations and evaluations have resulted in two evaluation reports on network-centric sharing of information, the use of information and the Eagle application during Eagle One (Brooijmans 2008; Van de Ven 2008), one technical evaluation of the Eagle application (Geodan 2008) and one evaluation of the emergency management in general during Eagle One (Van Capelleveen 2008) resulting in an overall evaluation of the use of geo-information and Geo-ICT in the Eagle One exercise (Riedijk et al. 2008). In this section, only the main findings are summarised according to networkcentric domain.

\section{Information Domain}

Through the information systems, the different units of the regional operational team were connected and were able to share information directly. Even though decision

Table 2 Respondents to the questionnaires

\begin{tabular}{lccr}
\hline Organisation & $\begin{array}{l}\text { SitPlot } \\
\text { Respondents }\end{array}$ & $\begin{array}{l}\text { SitText+SitPlot } \\
\text { Respondents }\end{array}$ & Total \\
\hline Fire brigade & 7 & 8 & 15 \\
Police & 2 & 3 & 5 \\
Paramedics & 1 & 2 & 3 \\
Municipality & 1 & 2 & 3 \\
Other & 3 & 4 & 4 \\
Unknown & 2 & 20 & 6 \\
Total & 16 & & 36 \\
\hline
\end{tabular}

Source: Brooijmans (2008). 
making still took place in a hierarchical way, the information could be shared more easily. In contrast with the established practices within the regional operational team, in which information was shared hierarchically from top to bottom or from bottom to top, information from one actor was now shared with other actors immediately. Moreover, more sources of information were available, since the regional actors were also connected to national and local geographical databases. In addition to having access to the information and the common operational picture that was derived from the information, participants could also contribute to the common picture from their own perspective.

Through this way of organising information, the required information was mainly available in the information system as was also illustrated by the response to questions related to the information domain. For example, more than $50 \%$ of the SitPlot respondents stated that all information needed was present in SitPlot and 83\% stated that this information supported their tasks. Nevertheless, some redundant information was also available in the system, since $64 \%$ agreed that some data layers would never be used. There was some variation in the assessment of accuracy of the data in the SitPlot system, however, with $21 \%$ agreeing that there was too much detail, $43 \%$ desired more detail. In addition, specific attention should be given to the accuracy of data, since $46 \%$ of the SitPlot respondents found errors in the data compared with $14 \%$ who did not and $40 \%$ who did not know or gave a neutral answer. In addition, data should be more up-to-date as was agreed by $54 \%$ of the SitPlot respondents although $23 \%$ disagreed. Related to this, only $36 \%$ of these respondents regarded the information in the system as valid and reliable compared with $14 \%$ who did not.

\section{Cognitive Domain}

It can be concluded that the Eagle system contributed to both a common operational picture and a shared operational awareness. This was best observed during the multidisciplinary meetings. Little time was spent on explaining the situation, but the actors immediately started to plan actions. In addition, the responses to the questionnaires suggested that also the actors themselves perceived an increased situational awareness. Almost three quarters of the SitPlot and SitText respondents (72\%) argued that other sections of the regional operational team had the same operational picture and $94 \%$ argued that actors in the same section had the same operational picture. Almost $90 \%$ of the SitPlot respondents argued that they had a better overview of what happened because information was shared through maps. Moreover, $86 \%$ of the SitText and SitPlot respondents agreed that they had a better operational picture through SitPlot and SitText.

The available information helped greatly to shape the situational awareness of the participants. Even though this contributed to a shared situational awareness, it also caused some problems during the exercise, especially when information was taken for granted. For example, participants focused on vulnerable people from nursing and elderly homes that were available in the database, while neglecting other groups of vulnerable people. Therefore a critical attitude towards the information available and presented in the information system is required. 
Physical Domain

In the end, improved information and communication should result in a shared situational awareness and to improved collaboration resulting in the reduction of the impact of an incident. It was difficult, however, to judge if the organisation of information and the geotechnology system being tested actually resulted in better actions and effects. The setup of the training did not allow for making a distinction between different but parallel groups through which results of the exercise with the information system could have been compared with groups who worked in a traditional way without the system. Undertaking the exercise with a network-centric approach and the information system was a general objective and, therefore, groups were not excluded from using the system. Nevertheless, results on the collaboration and shared situational awareness already indicated that the information contributed to a reduction of potential effects of an incident through improving the communication, information and, related to that, the situational awareness. In addition, the questionnaire results suggested that the system had contributed positively to decision making in general, since over $70 \%$ of the SitPlot and the SitPlot and SitText respondents agreed that the information system improved the quality of their work in general.

\section{Discussion}

Conceptualising risk and emergency management as a point of departure for developing information systems may look simple and straightforward in theory. However, it turned out to be difficult to do this in practice. Ideas on what risk management and emergency response is about or how it should be carried out are often implicit and hard to make explicit. It turned out to be useful to switch from particular conceptions derived from project meetings with developers and users within the project to a more general conception in the literature to develop an interpreting framework through which risk and emergency management as a process could be conceptualised. This way of developing an interpretative framework was referred to as abduction. The conceptualisation of risk and emergency management as network-centric operations turned out to be useful to understand risk and emergency management practices and to develop points of departure for the development of an information infrastructure through which geoinformation and geotechnology could be organised. The network-centric concept was useful as an overall concept to structure existing ideas on collaboration, shared situational awareness, information sharing, geotechnology and SIIs. Nevertheless, little was added to existing ideas on risk and emergency management or geotechnology and SII development. Its contribution to geotechnologies, for example, seemed limited, especially with respect to existing ideas on networks and services as developed in the field of SIIs (see, for example, Mansourian et al. 2006). Of course, the network-centric concept was useful in practice to convince the actors involved in emergency response of the need of information sharing and interoperability and consequently to create a shared situational awareness on how geoinformation and geotechnology should be organised. In the end, however, we 
believe that the added value of the network-centric approach goes beyond its value for marketing or structuring ideas.

A critical innovative aspect of the network-centric approach is its philosophy on information sharing. Whereas information was initially shared in an hierarchical way, the implementation of the network-centric approach resulted in a networkcentric dissemination of information through which new information on the actual situation of actions of other actors became available immediately to actors involved in emergency response through which actions could be adapted to both the new situation and the actions of other actors. This network-centric way of information sharing instead of a hierarchical way also triggered technological innovations, such as the implementation of a P2P network to guarantee a constant information exchange during emergencies. In addition, network-centric risk and emergency management can be regarded as another way of coordinating activities and of stimulating collaboration in risk and emergency management. Actual emergency management processes in the Netherlands are being criticised for its hierarchical topdown command structure. These commands are regarded as ineffective ways of coordination during emergencies (Scholtens 2008). Nevertheless, coordination is not necessarily achieved through central commands, but can also be stimulated through information sharing and the development of a common operational picture as assumed in the network-centric approach, which can support self-managing ways of collaboration as an alternative for collaboration through central commands and control (see also Scholtens 2008).

These principles and lessons as derived from the development of Eagle and the emergency training can also be relevant for risk management processes. Of course, it can be argued that relevant risk information for risk management is already becoming available and shared, e.g. through improved and increased risk assessment or through the worldwide development of spatial data clearinghouses as a main element of SIIs (Crompvoets et al. 2004). These existing information infrastructures, however, do often not meet the specific requirements needed for emergency response such as network stability or the speed of information availability and exchange (National Research Council 2007). Therefore, the organisation and development of geotechnology and geoinformation for risk management should also be considered in the light of the requirements for emergency management so that the information and networks can also be used during an emergency. Moreover, principles of a network-centric dissemination of information in risk management should be considered. In risk management practices, it is not uncommon that information is distributed hierarchically. Changes in the nature and amount of hazardous materials at a particular installation, for example, are often distributed hierarchically, e.g. from the plant operator to a National Health and Safety Executive, who should forward this information to a local planning department (Basta et al. 2007). Even though risk management practices are less time-critical, a network-centric organisation of information dissemination and information systems can still contribute to a more realistic picture of the safety risks of a particular area and consequently to an improved situational awareness which can result in improved collaboration and coordination and subsequently to more effective risk management. Outdated information, for example, can result into inappropriate safety distances or contingency plans. 
As mentioned earlier, the starting point of an abductive approach should be in the particular, situation specific phenomena and not in the existing and often general theories. Therefore, prudence for using the NCREM concept is called for, since a conceptualisation of risk and emergency management practices as network centric processes does not guarantee that information is spread in a network centric way. A critical approach towards actual, situation specific processes is therefore required. In this light, NCREM is more a target than an accurate description of risk and emergency practices. In addition, abduction does not result in general, but in context specific theories. Even though we regard the NCREM concept as valuable in general, it may need to be adapted to specific circumstances, for example when an immediate netcentric distribution of information conflicts with requirements on accuracy and validity. In such cases, a mixture between hierarchical and network centric ways of information dissemination can be considered. For example, information can be send to an information manager first, who validates the information and then sends the information to the actors involved.

Moreover, the interpretative framework should be tested in practice. Within this case study, for example, a SII based on NCREM principles was developed and tested. Even though the first results are promising, further evaluation of such systems is required. First of all, the investigation of information requirements needs to be refined. The case study showed that some information was redundant. Following an abductive approach, findings in practice can be combined with literature and findings from other practices to reduce redundancy and to increase the completeness of information. Second, the actual effects of having a common operational picture on the actions that are taken in the physical domain should be explored further. Within the Eagle One case, it was difficult to judge if the organisation of information resulted in better actions and effects. Therefore, trainings with parallel groups with and without the information system are desirable to study the effects of the information system on actions and the potential bottlenecks and mechanisms between information and action.

Moreover, more attention for the implementation of an information system that can support NCREM is required. Even though network-centric warfare has been highly technology driven (Von Lubitz et al. 2008a), we believe that the added value of the network-centric approach for the organisation of geotechnology in risk and emergency response lies in the network-centric organisation of information dissemination, which subsequently requires technology such as the development of services and networks. An exclusive focus on technology is therefore undesirable, since it can derive attention away from crucial organisational aspects. For example, people should be willing to share information in a network-centric way.

In addition, it can be argued that, according to network-centric emergency response principles, people with a better information position should be able to take better decisions. The central command can still give orders to lower level units about the objectives that should be achieved but these operational units do have the freedom to decide on how these objectives should be achieved as is worked out in the Netherlands defence doctrine (Ministry of Defence 2005). As stated by Von Lubitz et al. (2008a: 576), "the net effect of network-centricity is much greater operational and tactical freedom for the individual units that support the most effective execution of 'commander's intent' as well as operational coordination of all 
activities within the entire spectrum of the assigned missions". Clearly then, the elaboration of network-centric risk and emergency management is about both the organisation of information and about the organisation of risk and emergency management itself. Consequently, the development of geotechnology for risk and emergency management is not only about the information system or technology itself, but also about the way risks or emergencies can or should be addressed and dealt with, which requires a conception of risk and emergency management activities.

\section{Conclusions}

Risk and emergency management activities have been portrayed as network-centric operations in which collaboration and information exchange are required. Based on this conceptualisation of risk and emergency management practices, it has been argued that information should no longer be shared in a hierarchical way. Information should be shared and available at all levels at the same moment through information networks. The development and implementation of a spatial information infrastructure is desirable to organise geographical information for emergency management and to facilitate information sharing and integration during emergency preparation and response. Organising geographic information and geotechnology in a network-centric way can lead to improved information; improved communication; better situational awareness; better and faster decision making and more effective risk management and emergency response.

Acknowledgements We would like to thank the participants in the GeoRisk and GDI4DM project for their support for and contribution to this research. We also greatly appreciate the work of Patrick Brooijmans who carried out the evaluation of Eagle during the Eagle One exercise as part of his UNIGIS MSc. This research was funded by the Dutch innovation programme 'Space for Geoinformation', for which the authors are grateful. The GeoRisk projects started in 2005 and finished in 2008 (4 years) with a total budget of 0.5 million Euro. The GDI4DM project also started in 2005 and finished in 2008 with a total budget of 2 million Euro. The Eagle product suite for disaster management will become available worldwide, based on the cooperation between ESRI, Microsoft and Geodan.

Open Access This article is distributed under the terms of the Creative Commons Attribution Noncommercial License which permits any noncommercial use, distribution, and reproduction in any medium, provided the original author(s) and source are credited.

\section{References}

ACIR. (2005). De vrijblijvendheid voorbij. Op naar een effectieve multidisciplinaire informatievoorziening bij grootschalig gezamenlijk optreden in onze gedecentraliseerde eenheidsstaat. Den Haag: Ministerie van Binnenlandse Zaken en Koninkrijksrelaties.

Alberts, D. A., Garstka, J. J., Hayes, R. E., \& Signori, D. A. (2001). Understanding information age warfare. CCRP Publication Series.

Annoni, A., Bernard, L., Douglas, J., Greenwood, J., Laiz, I., Lloyd, M., et al. (2005). Orchestra: developing a unified open architecture for risk management applications. In P. Van Oosterom, S. Zlatanova, \& E. M. Fendel (Eds.), Geo-information for disaster management (pp. 1-17). Berlin: Springer. 
Basta, C., Neuvel, J. M. M., Zlatanova, S., \& Ale, B. (2007). Risk-maps informing land-use planning processes - a survey on the Netherlands and the United Kingdom recent developments. Journal of Hazardous Materials, 145(1-2), 241-249.

Bortenschlager, M., Leitinger, S., Rieser, H., \& Steinmann, R. (2007). Towards a P2P-based geocollaboration system for disaster management. In GI-Days, 2007, Munster.

Brooijmans, P. (2008). How to measure the added value of geographic information in Disaster Management. Msc. Thesis, Free University, Amsterdam.

COT, T. G., \& Haskoning, R. (2005). De organisatorische voorbereiding op overstromingen van Rijn en Maas. Den Haag: Ministerie van Binnenlandse Zaken.

Cova, T. J. (2005). GIS in emergency management. In P. A. Longley, M. F. Goodchild, D. J. Maguire, \& D. W. Rhind (Eds.), Geographical information systems: Principles, techniques, management, and applications (2nd ed., pp. 845-858). New York: Wiley.

Crompvoets, J., Bregt, A., Rajabifard, A., \& Williamson, I. (2004). Assessing the worldwide developments of national spatial data clearinghouses. International Journal of Geographical Information Science, 18(7), 665-689.

Cutter, S. L. (1996). Vulnerability to environmental hazards. Progress in Human Geography, 20(4), 529-539.

Danermark, B., Ekström, M., Jakobsen, L., \& Karlsson, J. C. (2002). Explaining society: Critical realism in the social sciences. London: Routledge.

Diehl, S., \& Van der Heide, J. (2005). Geo information breaks through sector think. In P. Van Oosterom, S. Zlatanova, \& E. M. Fendel (Eds.), Geo-information for disaster management (pp. 85-108). Delft: Springer.

Dilo, A., \& Zlatanova, S. (2008). Spatiotemporal modelling for disaster management in the Netherlands. In B. Van der Walle \& F. Friedrich (Eds.), Information systems for crisis response and management, Joint ISCRAM-CHINA GI4DM Conference (pp. 517-528). China: Harbin.

Drummond, W. J., \& French, S. P. (2008). The future of GIS in planning: converging technologies and diverging interests. Journal of the American Planning Association, 74(2), 161-175.

French, S., \& Niculae, C. (2005). Believe in the model: mishandle the emergency. Journal of Homeland Security and Emergency Management, 2(1), Article 2.

Fruijtier, S., Van der Zee, E., Gehrels, B., Zlatanova, S., Ryan, M., \& Scholten, H. J. (2009). Design, implementation and real-life evaluation of a disaster management architecture. In GISWORX 2009, Dubai.

Geodan (2008). Rapport Testverslag Realisatie CCS1.5 t.b.v. Eagle One, Versie 0.1, Geodan, Amsterdam.

Greene, R. W. (2002). Confronting catastrophe: A GIS handbook. Redlands: ESRI Press.

Grothe, M. J. M., Landa, H. C., \& Steenbruggen, J. G. M. (2008). The value of Gi4DM for transport and water management. In S. Zlatanova \& J. Li (Eds.), Geospatial information technology for emergency response (pp. 313-328). London: Taylor and Francis Group.

Kevany, M. J. (2003). GIS in the World Trade Center attack-trial by fire. Computers, Environment and Urban Systems, 27(6), 571-583.

Klosterman, R. E. (2001). Planning support systems: A new perspective on computer-aided planning. In R. K. Brail \& R. E. Klosterman (Eds.), Planning support systems, integrating geographical information systems, models and visualization tools (pp. 1-23). Redlands: ESRI press.

Köhler, P., \& Wächter, J. (2006). Towards an open information infrastructure for disaster research and management: data management and information systems inside DFNK. Natural Hazards, 38(1-2), $141-157$.

MacFarlane, R. (2005). A guide to GIS applications in integrated emergency management. Cabinet Office, Emergency Planning College.

Mansourian, A., Rajabifard, A., Valadan Zoej, M. J., \& Williamson, I. (2006). Using SDI and web-based system to facilitate disaster management. Computers and Geosciences, 32(3), 303-315.

Ministerie van Binnenlandse Zaken. (2003). Handboek rampenbestrijding. Den Haag: Ministerie van Binnenlandse Zaken.

Ministry of Defence. (2005). Netherlands defence doctrine. The Hague: Ministry of Defence.

National Research Council. (2007). Successful response starts with a Map. Improving geospatial support for disaster management. Washington: The National Academies Press.

Neuvel, J. M. M., \& Zlatanova, S. (2006). The void between risk prevention and crisis response. In UDMS'06 (pp. 6.1-6.14) Aalborg.

Parker, C. J., MacFarlane, R., \& Philips, C. (2007). Integrated emergency management: experiences and challenges of a national GI provider, Ordnance Survey. In S. Zlatanova \& J. Li (Eds.), GI-technology for emergency response (pp. 275-312). London: Taylor\& Francis.

Projectconsortium GeoRisk. (2008). Geo-informatie voor risicobeheersing. Wageningen: Land Use Planning Group. 
Riedijk, A., Brooijmans, P., Jacobs, C., Lassche, L., \& Verzandvoort, S. (2008). Evaluatierapport rampenoefening Eagle One. Amsterdam: Free University.

Scholten, H. J., LoCashio, A., \& Overduin, T. (1998). Towards a spatial information infrastructure for flood management in The Netherlands. Journal of Coastal Conservation, 4(2), 151-160.

Scholten, H. J., Fruijter, S., Dilo, A., \& Van Borkulo, E. (2008). Spatial data infrastructures for emergency response in the Netherlands. In S. Nayak \& S. Zlatanova (Eds.), Remote sensing and GIS technologies for monitoring en prediction of disasters (pp. 179-197). Berlin: Springer.

Scholtens, A. (2008). Controlled collaboration in disaster and crisis management in the Netherlands, history and practice of an overestimated and underestimated concept. Journal of Contingencies and Crisis Management, 16(4), 195-207.

Shulock, N. (1999). The paradox of policy analysis: if it is not used, why do we produce so much of it? Journal of Policy Analysis and Management, 18(2), 226-244.

Snoeren, G. (2006). Rampenbestrijdingsprocessen. Actoren, werkwijze en data. GDI4DM project, Arnhem.

Te Velde, H., Aarts, M. N., \& Van Woerkum, C. (2002). Dealing with ambivalence: farmers' and consumers' perceptions of animal welfare in livestock breeding. Journal of Agricultural and Environmental Ethics, 15(2), 203-219.

Van Capelleveen, E. (2008). De coctail maakt hét verschil. Overall evaluatie \& observatie oefening 'Eagle One en Gedeelde beelden'. Twynstra Gudde, Amersfoort.

Van de Ven, J. (2008). Evaluatie netcentrisch werken tijdens Eagle One. Concept. Soesterberg: TNO.

Van de Ven, A., \& Van den Berg, E. (2007). Evaluatie. Toetsing GDI binnen rampenoefening Voyager 2007. Den Haag: Ministerie van Volkshuisvesting, Ruimtelijke Ordening en Milieu.

Van de Ven, J., Van Rijk, R., Essens, P., \& Frinking, E. (2008). Network centric operations in crisis management. In ISCRAM Conference, Washington D.C.

Von Lubitz, D. K. J. E., Beakley, J. E., \& Patricelli, F. (2008a). 'All hazards approach' to disaster management: the role of information and knowledge management, Boyd's OODA loop, and networkcentricity. Disasters, 32(4), 561-585.

Von Lubitz, D. K. J. E., Beakley, J. E., \& Patricelli, F. (2008b). Disaster management: the structure, function, and significance of network-centric operations. Journal of Homeland Security and Emergency Management, 5(1), 1-24.

Walter, J. (2005). World Disasters Report 2005-data or dialogue? Geneva: International Federation of Red Cross and Red Crescent Societies.

Weiss, C. H. (1991). Policy research: data, ideas, or arguments? In P. Wagner, C. H. Weiss, B. Wittrock, \& H. Wollman (Eds.), Social science and modern states. National experiences and theoretical crossroads (pp. 307-332). Cambridge: Cambridge University Press.

Williamson, I., \& Rajabifard, A. (2003). Developing spatial data infrastructures: From concept to reality. London: Taylor \& Francis.

Zerger, A. (2002). Examining GIS decision utility for natural hazard risk modelling. Environmental Modelling and Software, 17(3), 287-294. 